\title{
An inquiry into the learning-style and knowledge-building preferences of interior architecture students
}

Halime Demirkan, Department of Interior Architecture and Environmental Design, Faculty of Art, Design and Architecture, Bilkent University, 06800 Bilkent, Ankara, Turkey

This study explores the learning-style and knowledge-building preferences of interior architecture students using Felder-Soloman's Index of Learning Styles. Considering the learning and knowledge-building skills of students in design education, this study concludes that the instructor should not only be a conveyor of knowledge but also a facilitator. The findings indicate that design students' preferred learning styles are as follows, in descending order: Sensing/Intuitive, Visual/Verbal, Active/Reflective and Sequential/Global. In the two-way analysis, where the student's design studio grade was the dependent variable, significant effects were obtained for each scale. Furthermore, double interactions were highly significant between the Active/Reflective and Sensing/Intuitive scales and between the Active/Reflective and Sequential/Global scales.

(C) 2016 Elsevier Ltd. All rights reserved.

Keywords: design education, design knowledge, information processing, learning style

Corresponding author: Halime Demirkan demirkan@bilkent. edu.tr
$\mathrm{W}$ e are living in a time where the world is constantly changing and evolving. In traditional design education, design knowledge was taught to students in a scheduled studio space for long blocks of time several periods a week. Students were encouraged to work in the studio and receive critiques from the instructor at several phases of the design process. With the emergence of digital technology, the design studio has changed from a studio-based learning environment to a technologyenhanced active learning space. Unfortunately, however, design education itself has not kept up with the changes in technology and in many cases does not enhance students' learning and the knowledge-building skills beyond predetermined, standardized boundaries. Recent studies have shown that the use of technology in the design studio supports interaction, active learning and social engagement, which are reflected in students' development of design knowledge (Cho, Cho, \& Kozinets, in press; Karakaya \& Demirkan, 2015; Mor \& Mogilevsky, 2013). Bearing in mind that design education needs to change to reflect this new learning style, design instructors must be forward thinking about how to educate, train and inspire the coming generation. 
Considering the learning and knowledge-building skills of students in design education, the instructor should not only be a conveyor of knowledge but also a facilitator, encouraging students to develop their academic and artistic skills.

The design process is comprised of strategies to determine a solution(s) to a problem. Therefore, the design process should ensure that the correct problem is being solved. In the design process, information processing and decision making is very intensive in the conceptual design phase, as a consequence of generating and evaluating alternative ideas. An epistemological and methodological approach guides the designer to capture, describe, prioritise, act and evaluate alternative design solutions (Demirkan, 2015). Therefore, it is important that methods and knowledge are linked in designers' cognitive strategies. During the design process, the designer constructs a conceptual model of an artifact by abstracting knowledge from previous experiences and information stored in his or her memory. These conceptual representations are linked both with external forms of knowledge, as sketches or architectural drawings, and with internal representations of the model, as visual imagery. Studies have shown that people have different ways of receiving and processing information (Litzinger, Lee, Wise, \& Felder, 2007; Smith \& Kolb, 1996), and previous researches confirm that this also applies to students going through the design process (Carmel-Gilfilen, 2012; Demirkan \& Demirbas, 2008; Kvan \& Yunyan, 2005). Incorporating learning styles in design-studio instruction may make learning easier and lead to better student performance.

This study investigates the learning-style and knowledge-building preferences of today's interior architecture students in the design studio. The findings are expected to provide a better understanding of how to expand the design studio as a high-performing and technology-rich learning space.

\section{Previous studies related to learning styles in design education}

Learning in design is an internal process that is different for each student. A student's preferred method for receiving information in any learning environment is his or her learning style. As evident from the literature, various learning-style models are employed in design education. The most common models are the Myers-Briggs Type Indicator (MBTI) (Durling, Cross, \& Johnson, 1996; Russ \& Weber, 1995), Kolb's Learning Style Inventory (K-LSI) (Carmel-Gilfilen, 2012; Demirbas \& Demirkan, 2003, 2007; Demirkan \& Demirbas, 2008; Kvan \& Yunyan, 2005; Newland, Powell, \& Creed, 1987; Tucker, 2007, 2009) and Felder-Soloman's Index of Learning Styles (ILS) (Demirkan \& Demirbas, 2010; Felder \& Spurlin, 2005; Mostafa $\&$ Mostafa, 2010). One of the main motivations behind such models is to identify characteristics of preferred learning styles. Once identified, learning 
preferences can be instrumental in designing teaching methods to improve knowledge acquisition.

To classify students, the MBTI uses four scales derived from Jung's Theory of Psychological Types: Extroverts/Introverts, Sensors/Intuitors, Thinkers/ Feelers and Judgers/Perceivers (Felder \& Brent, 2005). Russ and Weber (1995) used the MBTI to examine the personality traits of 234 interior design students at 12 accredited universities in the US. They reported that the students primarily used abstract information, that their judgements were based on feeling and that they relied on their instincts in design process. Also using the MBTI, Durling et al. (1996) reported that it is possible to differentiate designers from other professionals. Furthermore, Durling et al. (1996) explored the cognitive styles of design students and determined that there is a match between teaching and learning styles in UK design schools.

The K-LSI is the most widely used learning style inventory in the design discipline, and identifies four types of learning styles: Accommodating, Converging, Diverging and Assimilating. Newland et al. (1987) identified four types of design styles using the K-LSI in an empirical study of practicing architects, the goal of which was to improve design information transfer. Using K-LSI, design educators have also started to explore learning-style characteristics that can develop better learning in design (Carmel-Gilfilen, 2012; Demirbas \& Demirkan, 2003, 2007; Demirkan \& Demirbas, 2008; Kvan \& Yunyan, 2005). Demirbas and Demirkan's studies $(2003,2007)$ showed that the distribution of design students across learning-style preference was more concentrated in Assimilating and Converging groups. In a subsequent study, they concluded that interior architecture students have balanced learningstyle preferences (Demirkan \& Demirbas, 2008), drawing from all four styles in their learning. Carmel-Gilfilen (2012) also uncovered the presence of all learning styles in interior design students, but with a preference toward Diverging and Accommodating groups.

Demirbas and Demirkan's studies with the K-LSI $(2003,2007)$ found that there were statistically significant differences among the performance scores of design students with diverse learning styles. The findings of Kvan and Yunyan (2005) also showed a correlation between learning style and performance scores in the design studio.

Tucker (2007) compared learning-style preferences of first- and third-year design students using the K-LSI, where each group was composed of students from architecture, construction management and a combination of the two programs. His findings related to first-year architecture students parallelled Demirbas and Demirkan's study (2003), and found emphasized differences in learning-style preferences related to years in multi-disciplinary collaborative design studios. 
Felder-Soloman's ILS identifies eight types of learning and places them on four scales: Active/Reflective, Sensing/Intuitive, Visual/Verbal and Sequential/Global. Using the ILS, Mostafa and Mostafa (2010) compared firstand third-year architecture students with the general population of students at the American University in Cairo. Their findings indicated, 'that architecture students are predominantly better visual learners than general students, and their visual learning skills increase as they move through the program' (Mostafa \& Mostafa, 2010: 313). Architecture students used active learning rather than reflective learning more than the general population did. However, the increase in active learning was lower than the increase in visual learning as students moved through the program. Demirkan and Demirbas (2010) used Felder and Silverman's (1988) ILS, which is an earlier version of Felder and Soloman's (2004) ILS, to assess the learning preferences of fourth-year design students. The findings indicated that the usual methods of design education address a balanced class position on the Active/Reflective and Sensing/Intuitive scales, a moderate to strong preference on the Visual scale and a weak preference on the Global scale.

The current study focuses on Felder and Soloman's four scales of ILS to provide a more detailed description of students' learning styles. Each scale is composed of 11 items that identify the specific learning characteristics of each style. Further analysis of ILS results shows how representative each item is for each learning scale. Identifying items from a particular learning style and where it is on the scale leads to better planning of teaching methods and in choosing the relevant content and sources for design studios.

\section{Learning and knowledge-building processes in design education}

Based on previous studies related to learning styles in design education, this study revised Felder-Soloman's ILS and adapted its usage to determine the learning styles and knowledge-processing acts of interior architecture students. In this study, the four scales of ILS are grouped into two categories: learning styles (knowledge perceiving) and thinking styles (knowledge processing). In this revised model, learning style is displayed by how students perceive information (sensorially or intuitively) through their preferred channels (visual or verbal). Thinking style is displayed by their preference in processing information (actively or reflectively), determined by their progression (sequential or global) in understanding the information. In this section, firstly ILS is introduced in detail while explaining the scales of ILS with their corresponding equivalences in the design domain.

In design education, learning and knowledge-building methods aim to balance the creative design process with a critical awareness of the more objective criteria necessary for project development as a whole. The learning process 
is characterized by continual dialogue between students and instructors. This acquired information is reflected in students' drawings and models and raises the project quality.

In the design studio, students receive and process information according to their learning preferences. In the reception phase, processed information can be available to students through external or internal channels. In the processing phase, Schon (1983: ix) stated that learning in the design studio is developed through a process called 'reflection-in-action' and the role of the learner is defined as an active practitioner. During the design process, a given design problem is turned into a design solution, and a continuous dialogue between the student and instructor enhances the design progression. Therefore, the learning experience is based on self-reflection. In the design-studio process, there should be a developmental trajectory leading from the natural inquisitiveness of the designer (the student) to the disciplined creativity of the knowledge producer (the instructor). Knowledge building may be defined as the production and continual improvement of design ideas. As applied to interior design education, this can be achieved by focussing on all learning activities that can lead to knowledge building rather than engaging only in learningby-doing activities, which has been typical in design education.

The information processing phase involves simple memorization and reasoning, reflection and action, as well as introspection and/or interaction with others in design activities where the amount depends on the individual's learning style. In this phase, a designer uses previous knowledge obtained from observed and derived facts that are deduced through a justified mode of inference (i.e. inductive, deductive or abductive). The designer as an interpreter defines how a reasoning mode should be used to achieve the desired ends, and sets the goals and objectives. Sometimes priorities need to be determined and applied in order to select between competing knowledge sources (Demirkan, 1998).

According to the model developed by Felder and Silverman (1988) and later modified (Felder \& Soloman, 2004), learning styles may be defined by four scales that identify a student's preference in perceiving, processing and understanding information as well as his or her preference of information input channel. Figure 1 shows the four scales of Felder-Soloman's ILS that is revised by the author and the related learner type is explained in detail within the context of the design process. In the revised model, learning style is associated with mental acts that influence the acquisition and internalisation of knowledge, whereas the knowledge-building process is associated with mental acts that influence processing, reframing and externalisation of knowledge.

Felder-Soloman's ILS incorporates four dimensions, where two are similar in some aspects to the dimensions of the Myers-Briggs and Kolb models. The 
Figure 1 The revised four scales of Felder-Soloman's Index of Learning Styles (ILS)

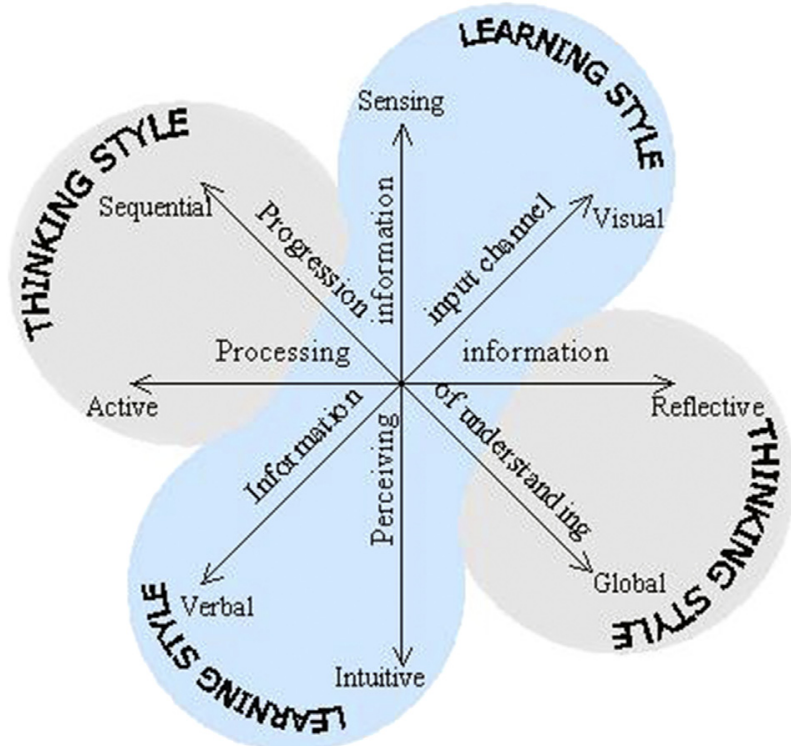

perceiving scale (Sensing/Intuitive) is analogous to both Myers-Briggs' and Kolb's 'perception' dimension, and the processing scale is also found in Kolb's model. Perception and processing are highly associated with the learning-style preferences of design students. The ILS has two additional scales, namely processing information (Active/Reflective) and the progression of understanding (Sequential/Global), which can be classified as dimensions of knowledgebuilding acts. Since it is important how methods and knowledge are linked within designers' cognitive strategies, these two scales are essential in linking conceptual representations both with external forms of knowledge such as sketches or architectural drawings and with internal representations of a model, such as visual imagery.

In the following paragraphs, ILS' four learning scales are explained within the scope of design education, where learning style is associated with mental acts that influence the acquisition and internalisation of knowledge (represented by the Sensing/Intuitive and Visual/Verbal scales of ILS). The knowledgebuilding process is associated with mental acts that influence processing, reframing and externalisation of knowledge and depicted by the Active/Reflective and Sequential/Global scales of ILS.

\subsection{Sensing and intuitive learners (preference in perceiving information)}

Learners who prefer a sensing learning style like facts, data and concrete material. They approach a solution in the design process with standard approaches and engage in the details of architectural elements. Since these 
learners like to relate learned material to real world, their approaches to design solutions are practical.

Learners who prefer an intuitive learning style like to study abstract material, such as principles and theories, and explore their underlying meanings. Their approach to design solutions is innovative and creative, incorporating new concepts. They do not like to repeat previous design solutions. Felder and Silverman (1988: 676) stated that 'sensors are careful but may be slow; intuitors are quick but may be careless'. Therefore, the duration of the design process may be longer for a sensor than an intuitor. Lawson (1993) also observed that compared to other disciplines architecture students tended to use more intuitive approaches when engaging with design. In a previous study based on the K-LSI, Demirkan and Demirbas (2008) found that freshman design students were balanced in the perceptive dimension, which has learning-bythinking and learning-by-doing as its poles.

\subsection{Visual and verbal learners (preference in information input channel)}

Visual learners prefer acquiring information through pictures, diagrams, videos and films, remembering information better this way. Visual learners 'provide cognitive-level representations that support memory, language and thought' (Barsalau, Simmons, Barbey, \& Wilson, 2003: 85). Conversely, verbal learners prefer either textual or oral presentations, remembering much of what they learn through reading or hearing. According to Demirkan and Demirbas (2010), fourth-year design students had moderate to strong preferences on the ILS visual scale. A design student's most important tool is the sketch, which is an outcome of a mental imagery process. Sketches quicken the design process and help both in developing a solution and in modifying it to a better alternative. Therefore, design students are familiar with visual information and perceive visual presentations effectively.

\subsection{Active and reflective learners (preference in processing information)}

Active learning involves hands-on activities, such as drawing or constructing a 3D model and discussing, explaining and/or testing it. Active learners grasp their environments concretely through feelings and utilize action to transform the information obtained (Demirbas \& Demirkan, 2003). They tend to solve design problems by trial-and-error methods. They rely on others for information instead of making any research on their own and enjoy working in groups. Reflective learning, on the other hand, involves examining and manipulating information introspectively. Such learners prefer to work alone or with familiar partners. Traditional educational settings where lectures are dominant in information transfer are not suitable for active learners, since they do not process information well in this way. Lectures are also not suitable 
for reflective learners because they do not provide the opportunity to think about the information presented at the time.

Active learning involves students doing something beyond listening and/or watching. It involves discussing, questioning, commenting, criticizing, brainstorming and reflecting. Active and reflective learners are both needed as designers, and instructors should be able to teach to and encourage such skills in their students. Schon (1983) described the design instructor as a facilitator who provides information and resources to students for professional growth.

\subsection{Sequential and global learners (progression of understanding the relevant information)}

Sequential learners best understand the relevant information through linear progression. They learn best when material is presented in incremental steps in terms of complexity and difficulty. They follow a linear reasoning process when problem solving. Global learners, however, first understand the relevant information as a whole rather than as parts. They can learn broad knowledge easily but it may take time to apply that knowledge to a solution. Sometimes they may not be able to explain how they reached that solution, as they can be weak in making connections in terms of the reasoning process. Global learners are interested in the final solution, but not in the details. In their model, Smith and Kolb (1996) stated that the converging learners (sequential learners) are organized and they can focus their knowledge on a specific problem. Hsu (1999) said that diverging learners (global learners) have the ability to synthesize and adapt a wide range of different information into a comprehensive explanation that enables them to generate new ideas.

The aim of this study is to examine the learning and knowledge-building preferences of interior architecture students. Consequently, it investigates students' learning-style preferences on a scale related to their preferred information input channel (visual to verbal) and modes of perception (sensing to intuition). Also, this study examines students' knowledge-building preferences in processing information (active to reflective) and in their progression of understanding the information (sequential to global). Furthermore, it analyzes differences between the knowledge-building and learning-style preferences between junior and senior interior design education students. Therefore, the current study builds upon the four scales of ILS to explore the learning and knowledge-building preferences of interior architecture students as well as to determine differences in scales between junior- and senior-year students. Through this way, a comprehensive view of design epistemology that can be used to positively affect interior architecture design education could be gained. 


\section{Interior architecture and environmental design education}

The aim of an interior architecture and environmental design program is to graduate qualified and experienced designers who will enhance the function and quality of interior spaces to improve quality of life, increase productivity and protect the public's health, safety and welfare. Design education's main philosophy is to educate students who can synthesize the acquired knowledge and solve design problems from various points of view. Cognizant of the impacts of new technologies and knowledge sources on the design profession, instructors should provide students with a well-rounded education that supports these changes.

The rationale of a design curriculum is to enable students to develop a learning model that will guide them to understand and apply the knowledge, skills, processes and theories of interior design so as to provide a balanced synthesis between the artistic, technological and human aspects of the profession. Considering students' learning and knowledge-building skills in interior architecture and environmental design education, the instructor's should not only be a conveyor of knowledge but also a facilitator.

The design studio process is at the core of the design curriculum and all courses taught in design education are related to the studio (Demirbas \& Demirkan, 2003). The learning process is characterized by continual dialogue, where students learn from sharing information with one another and the instructors. The assessment process is also a considerable part of the learning process. Visiting critics, instructors and peers all contribute to assessing students' work, commenting on and discussing issues to raise the quality of the project (Demirbas \& Demirkan, 2007).

Many studies using the ILS and findings related to engineering, business and science students have been published (Felder \& Spurlin, 2005). The current study was conducted with a sample of first- and fourth-year interior architecture students. An experiment was designed to answer the following research questions:

1. What learning-style preferences do undergraduate interior architecture students display

a) in perceiving information (sensing/intuition)?

b) in information input channel (visual/verbal)?

2. What knowledge-building preferences do undergraduate interior architecture students display

a) in processing information (active/reflective)?

b) in the progression to understand relevant information (sequential/ global)? 
3. Is there any significant difference between the first- and fourth-year interior architecture students in the four learning scales?

4. Is there any significant difference according to gender in the learning scales of interior architecture students?

5. How do interior architecture students prioritize the four learning scales and their related items?

6. Are there any significant differences in the design studio grades of students across the learning scales?

\section{Method}

\subsection{Participants}

This study was conducted with a sample of 218 students in the Department of Interior Architecture and Environmental Design at Bilkent University in Ankara, Turkey. The age range was between 18 and 28 years, with a mean of 21.06 years (st. dev. 1.73). The participants comprised 50 males and 168 females in total, with118 first-year ( 25 males and 93 females) and 100 fourthyear (25 males and 75 females) students. A stratified sampling method was conducted among all students, and they were informed that the results of the survey would not affect their academic results. Participants were told their learning-style preferences at the end of the study.

\subsection{Instrument}

The interior architecture students' learning styles were determined using Felder and Soloman's (2004) ILS, which contains 44 items on four scales (Active/Reflective, Sensing/Intuitive, Visual/Verbal, and Sequential/Global), each scale having 11 items. Litzinger et al. (2007) analysed 1000 students from three colleges (engineering, liberal arts and education) and reported that the Sensing/Intuitive and Visual/Verbal scales were both found to have Cronbach alpha reliability values in excess of 0.7 , whereas the Active/Reflective and Sequential/Global scales had alphas of 0.60 and 0.56 , respectively. The authors stated that the Cronbach alphas obtained in their study showed a similar pattern to previous studies in the literature and were mostly comparable in magnitude. Using the K-LSI, Demirbas and Demirkan (2007) investigated the learning styles of 273 interior architecture freshman students and reported that the alpha values ranged from 0.51 to 0.73 across the four learning style scales (Accommodating, Diverging, Assimilating and Converging). Tuckman (1999) suggested that an alpha of 0.50 or greater is acceptable for attitude and preference assessments, and thus as the alpha values of both instruments (ILS and K-LSI) have been consistently shown to be above 0.50 with similar magnitudes, these scales appear to be valid.

In the 44-item ILS, each item contains a sentence that can be answered by choosing one of two options, where each option represents the opposite end 
of a learning scale. In this way, a student's preference in each scale is determined. According to the ILS method (Litzinger et al., 2007), the polarity of a scale depends on the score from 1 to 11 . If the score on a scale is between 1 and 3 , it is balanced on the two dimensions of that scale. If the score on a scale is between 5 and 7 , there is a moderate preference for one dimension of the scale. If the score on a scale is between 9 and 11, there is a strong preference for one dimension of the scale.

As each scale is bipolar, a weight between 1 and 5 is assigned to these groups for coding purposes. For example, on the Active/Reflective scale, a very strong Active preference is coded as 5 , a moderate Active preference as 4 , a balanced Active or a Reflective preference as 3, a moderate Reflective preference as 2 and a strong Reflective preference as 1 . Therefore, code 1 is the pole for the Reflective preference and code 5 is the pole for the Active preference.

In this study, the students' design studio grades were analysed with respect to their learning scales. Bilkent University's grading system uses letter grades with pluses and minuses for performance scores. Passing grades range from ' $A$ ' to ' $D$ ' and ' $F$ ' is a failing grade. The highest grade is ' $A$ ' while the lowest is ' $\mathrm{F}$ ' and each grade has a quality point equivalence $(\mathrm{A}=4.0, \mathrm{~A}-=3.7$, $\mathrm{B}+=3.3, \mathrm{~B}=3.0, \mathrm{~B}-=2.7, \mathrm{C}+=2.3, \mathrm{C}=2.0, \mathrm{C}-=1.7, \mathrm{D}+=1.3$, $\mathrm{D}=1.0, \mathrm{~F}=0.0$ ).

\section{Results}

\subsection{Learning-style characteristics according to year}

Using the ILS, the distribution of the first and fourth year interior architecture students according to the four scales with the relevant mean scores and standard deviations were determined (Table 1). Firstly, it was tested if there was a difference between first- and fourth-year students in the four scales. According to Levene's test for equality of variances, showing the $\mathrm{p}$ values for the Active/ Reflective scale $(p=0.482)$, Sensing/Intuitive scale $(p=0.702)$, Visual/Verbal scale $(p=0.743)$ and Sequential/Global scale $(p=0.700)$ that were not significant, equal variances are assumed for the four scales. Consequently, the $t$

Table 1 Means and standard deviations of the four scales

\begin{tabular}{lcccc}
\hline & Year & $N$ & Mean & Std. deviation \\
\hline Active/Reflective & 1 & 118 & 3.08 & 0.718 \\
Sensing/Intuitive & 4 & 100 & 3.04 & 0.681 \\
Visual/Verbal & 1 & 118 & 3.11 & 0.845 \\
& 4 & 100 & 3.13 & 0.861 \\
Sequential/Global & 1 & 118 & 4.13 & 0.863 \\
& 4 & 100 & 2.16 & 0.838 \\
& 1 & 118 & 2.88 & 0.654 \\
\hline
\end{tabular}


values through equal-variance tests are determined. The learning-style preference did not differ significantly among the Active/Reflective, Sensing/Intuitive, Visual/Verbal and Sequential/Global scales according to year.

\subsection{Learning style distribution of students}

Using the ILS, the distribution of interior architecture students according to the four scales with the relevant scores was determined (Figure 2). Since each scale is considered to be bipolar dimensions, balanced/moderate/strong preference for each category is determined in order to specify the position of the interior architecture students on each scale. The mean score for Active/ Reflective learners was 3.06, for Sensing/Intuitive learners 3.12, for Visual/ Verbal learners 4.14 and for Sequential/Global learners 2.89. The mean of Active/Reflective, Sensing/Intuitive and Visual/Verbal learners to be above 3 shows the students are in favour of the active, sensing and visual preferences. As Sequential/Global learners with a mean score 2.89, they are in favour of global preference.

A one-way correlated analysis of variance showed a significant learning-style effect for the four learning scales $\left(F_{3,217}=117.98, p<0.001\right)$, partial $\eta^{2}=0.35$. Since the $\mathrm{p}$ value is less than 0.001 , it can be concluded there is a statistical significant difference in the mean scores of the four learning scales. The mean score for Active/Reflective learners is 3.06, for Sensing/Intuitive learner 3.12, for Visual/Verbal learners 4.14 and for Sequential/Global learners 2.89.

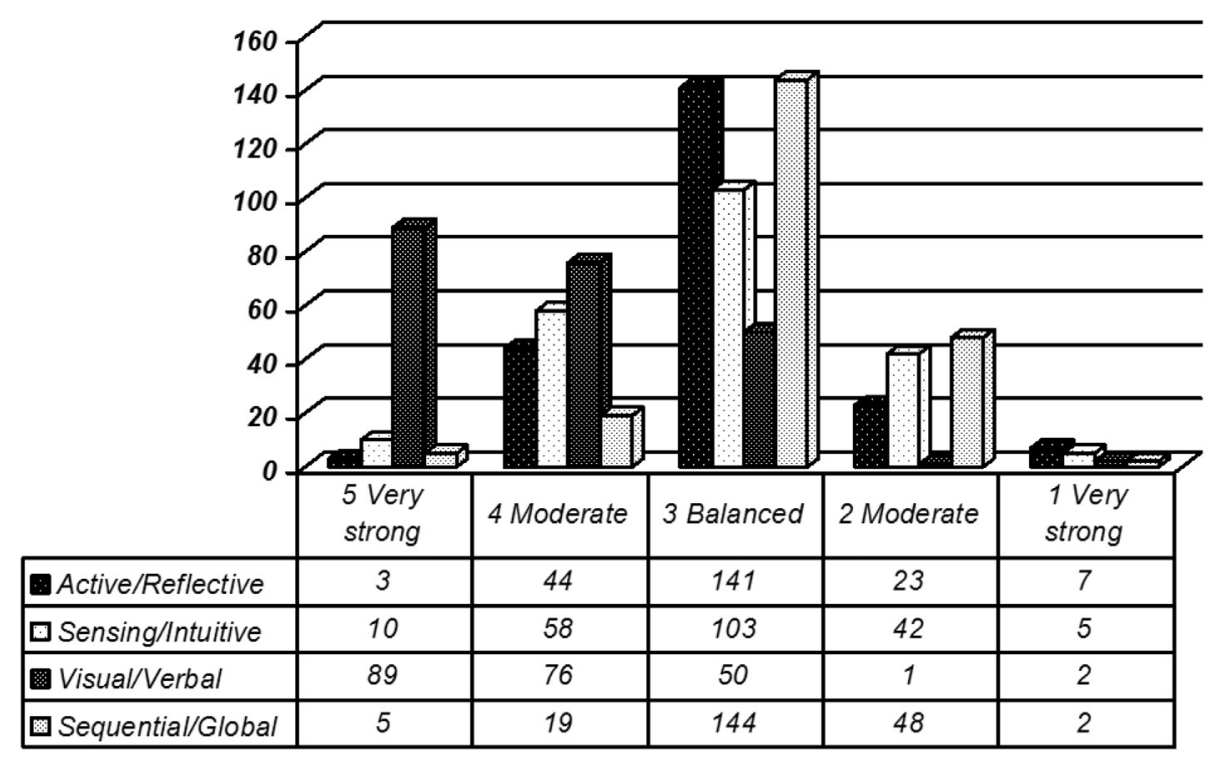

Figure 2 Classification of interior architecture students using the ILS 


\subsection{Learning-style characteristics according to gender}

Using the ILS, the distribution of gender of the interior architecture students through the four learning scales with the relevant scores was determined (Table 2) and the mean for each scale with respect to gender was calculated.

Learning-style preference did not differ significantly among the Active/Reflective, Visual/Verbal and Sequential/Global scales according to gender. There was, however, a gender difference only in the Sensing/Intuitive scale, with the mean Sensing/Intuitive scores of males $(\mathrm{M}=3.38$, st. dev. $=0.88)$ significantly higher $(\mathrm{t}=2.50, \mathrm{df}=216$, two tailed $\mathrm{p}=0.013)$ than those of females $(\mathrm{M}=3.04$, st. dev. $=0.83)$.

\subsection{Analysis of each ILS}

The internal consistency of each ILS scale was tested with Cronbach's alpha, and the responses were as follows: Active/Reflective (0.47), Sensing/Intuitive (0.66), Visual/Verbal (0.52) and Sequential/Global (0.27). Thus, the internal consistency reliability was weak, especially for the Sequential/Global group.

Litzinger et al. (2007) studied the reliability and validity of the Felder-Soloman ILS on data collected from engineering, liberal arts and education students. They found that the reliability of Sensing/Intuitive and Visual/Verbal scales was above 0.7, while the Active/Reflective and Sequential/Global scales had 0.60 and 0.56 Cronbach alphas, respectively. The alpha values found in this study were lower than those of Litzinger et al.'s (2007) study. The values of the Active/Reflective and Sequential/Global scales did not meet Schmitt's (1996) criterion, which states that an alpha value of 0.50 or greater is acceptable for preference studies.

Factor analysis was used on the data to test the validity of the ILS with the interior architecture students (Tabachnick \& Fidell, 1996). Factor analysis was performed to gain insight and relevance of possible contributing items to students' preferences in design education.

Table 2 The distribution of gender through learning scales

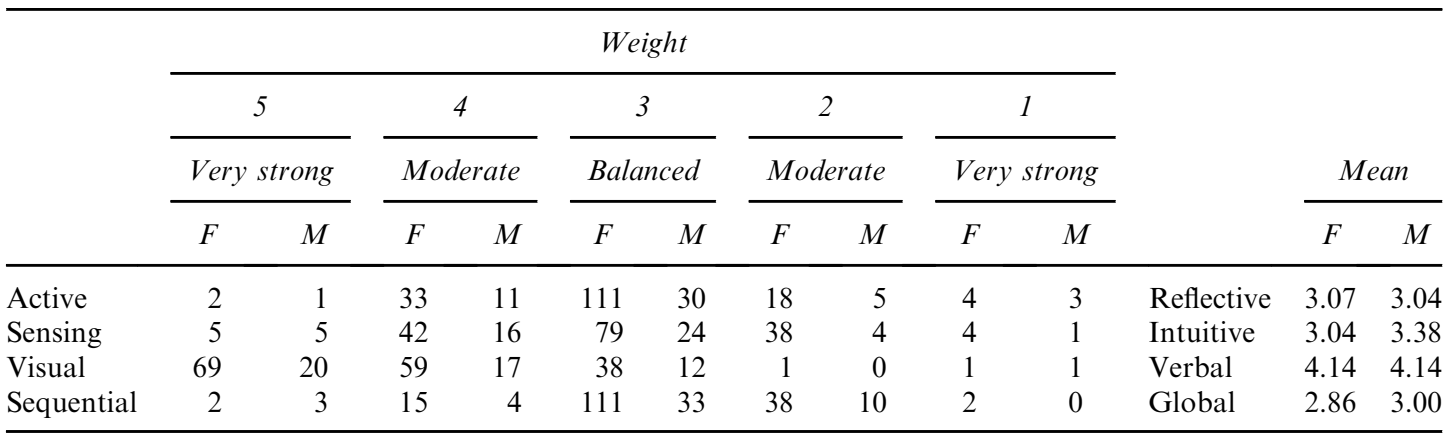


Principal component factor analyses were conducted for each of the four 11item ILS scales. Table 3 shows the item distribution, with each item included in the factor with the highest loadings. All items were positively correlated with the other items. The five items with the highest loadings from each scale were selected for inclusion in the revised version of the ILS.

The Active/Reflective scale is related to preference in information processing. Active learners prefer to work in groups or in a team. Reflective learners prefer to work alone or in a small group. It can be seen that the first-ranked item

Table 3 The five most representative items for each scale

\begin{tabular}{|c|c|c|c|c|}
\hline & Rank & Item & Loading & Question (Felder \& Soloman, 2004) \\
\hline \multirow{6}{*}{$\begin{array}{l}\text { Active/ } \\
\text { Reflective }\end{array}$} & 1 & 41 & 0.805 & \\
\hline & & & & the entire group, a) appeals to me. b) does not appeal to me. \\
\hline & 2 & 5 & 0.732 & $\begin{array}{l}\text { When I am learning something new, it helps me to a) talk about it. } \\
\text { b) think about it. }\end{array}$ \\
\hline & 3 & 21 & 0.681 & I prefer to study a) in a study group. b) alone. \\
\hline & 4 & 29 & 0.565 & $\begin{array}{l}\text { I more easily remember a) something I have done. b) something I } \\
\text { have thought a lot about. }\end{array}$ \\
\hline & 5 & 37 & 0.561 & I am more likely to be considered a) outgoing. b) reserved. \\
\hline Sensing/ & 1 & 18 & 0.823 & I prefer the idea of a) certainty. b) theory. \\
\hline \multirow[t]{4}{*}{ Intuitive } & 2 & 6 & 0.776 & $\begin{array}{l}\text { If I were a teacher, I would rather teach a course a) that deals with } \\
\text { facts and real life situations. b) that deals with ideas and theories. }\end{array}$ \\
\hline & 3 & 30 & 0.753 & $\begin{array}{l}\text { When I have to perform a task, I prefer to a) master one way of doing it. } \\
\text { b) come up with new ways of doing it. }\end{array}$ \\
\hline & 4 & 26 & 0.714 & $\begin{array}{l}\text { When I am reading for enjoyment, I like writers to a) clearly say what } \\
\text { they mean. b) say things in creative, interesting ways. }\end{array}$ \\
\hline & 5 & 38 & 0.506 & $\begin{array}{l}\text { When I am learning something new, it helps me to a) talk about it. } \\
\text { b) think about it. }\end{array}$ \\
\hline \multirow{6}{*}{$\begin{array}{l}\text { Visual/ } \\
\text { Verbal }\end{array}$} & 1 & 3 & 0.854 & When I think about what I did yesterday, I am most likely to get \\
\hline & & & & a) a picture. b) words. \\
\hline & 2 & 27 & 0.702 & $\begin{array}{l}\text { When I see a diagram or sketch in class, I am most likely to remember } \\
\text { a) the picture. b) what the instructor said about it. }\end{array}$ \\
\hline & 3 & 7 & 0.660 & $\begin{array}{l}\text { I prefer to get new information in a) pictures, diagrams, graphs, or maps. } \\
\text { b) written directions or verbal information. }\end{array}$ \\
\hline & 4 & 31 & 0.587 & $\begin{array}{l}\text { When someone is showing me data, I prefer a) charts or graphs. b) text } \\
\text { summarizing the results. }\end{array}$ \\
\hline & 5 & 15 & 0.537 & $\begin{array}{l}\text { I like teachers a) who put a lot of diagrams on the board. } \\
\text { b) who spend a lot of time explaining. }\end{array}$ \\
\hline \multirow[t]{5}{*}{$\begin{array}{l}\text { Sequential/ } \\
\text { Global }\end{array}$} & 1 & 28 & 0.778 & $\begin{array}{l}\text { When considering a body of information, I am more likely to a) focus } \\
\text { on details and miss the big picture. }\end{array}$ \\
\hline & 2 & 4 & 0.739 & $\begin{array}{l}\text { b) try to understand the big picture before getting into the details. } \\
\text { I tend to a) understand details of a subject but may be fuzzy about its } \\
\text { overall structure. b) understand the overall structure but may be fuzzy } \\
\text { about details. }\end{array}$ \\
\hline & 3 & 8 & 0.733 & $\begin{array}{l}\text { Once I understand a) all the parts, I understand the whole thing. b) the } \\
\text { whole thing, I see how the parts fit. }\end{array}$ \\
\hline & 4 & 24 & 0.580 & $\begin{array}{l}\text { I learn a) at a fairly regular pace. If I study hard, I'll 'get it.' b) in fits and } \\
\text { starts. I'll be totally confused and then suddenly it all 'clicks.' }\end{array}$ \\
\hline & 5 & 32 & 0.540 & $\begin{array}{l}\text { When writing a paper, I am more likely to a) work on (think about or } \\
\text { write) the beginning of the paper and progress forward. b) work on (think } \\
\text { about or write) different parts of the paper and then order them. }\end{array}$ \\
\hline
\end{tabular}


shows whether in this study doing homework in groups appeals $(49.1 \%)$ or not $(50.9 \%)$ to students, and the third-ranked item shows whether students like to work alone $(32.6 \%)$ or in a team $(67.4 \%)$ in the design process. Active learners tend to understand and learn information best by doing something active, such as discussing or applying the material, and reflective learners prefer to think about the learned material before applying it. The second-ranked item shows whether when students learn something new they want to talk about it (42.7) or think about it $(57.3 \%)$, and the fourth-ranked item shows whether students remember things they have done $(83.0 \%)$ or thought about them $(17 \%)$. The fifth-ranked item reflects students' social behaviour, that is, whether they consider themselves outgoing $(67.9 \%)$ or reserved $(32.1 \%)$.

The Sensing/Intuitive scale is related to preference in perceiving information. Sensing learners prefer to learn facts and solve problems by well-established methods and intuitive learners prefer to investigate possibilities and relationships. Four out five items are related to information preference in learning and teaching. The first-ranked item shows whether students prefer the idea of certainty $(71.6 \%)$ or theory $(28.4 \%)$. The second-ranked item shows whether would prefer to learn concrete materials like facts and data (74.8\%) or abstract materials such as concepts and theories $(25.2 \%)$. The fourthranked item concerns reading, that is, whether they prefer to read clearly stated material $(33.5 \%)$ or creative/interesting material $(66.5 \%)$. The fifthranked item shows how many students prefer to talk about new material while learning it $(61.5 \%)$ or think about it (38.5). The third-ranked item is related to preference type while performing a task, that is, whether students prefer to do it one established way $(33.5 \%)$ or try to do it in new ways $(66.5 \%)$.

The Visual/Verbal scale is related to preference of information input channel. Visual learners learn better by seeing pictures, diagrams, flow charts and films and verbal learners learn better through written and spoken explanations. The first- and second-ranked items are related to recognition of $(85.8 \%$ as pictures; $13.8 \%$ as words) and remembering information ( $74.3 \%$ as pictures; $25.7 \%$ as words). The third-, fourth- and fifth-ranked items are related to preference of information type in acquiring new knowledge. The students in this study showed higher preferences for pictorial information (89.9\%), visual data presentation $(81.2 \%)$ and visual teaching methods $(56.4 \%)$ rather than text or verbal explanations.

The Sequential/Global scale is related to preferences in the progression of understanding relevant information. Sequential learners tend to learn using linear steps in a logical order or pattern and global learners learn better by understanding the 'big picture' and then linking concepts. The first- and second-ranked items relate to understanding relevant information mainly while focussing on the big picture $(72 \%)$ or the overall structure $(61 \%)$ rather than on the details. The third-ranked item shows how many students learn 
better by understanding the whole concept first and then breaking down the parts within it $(61 \%)$. The fourth-ranked item shows that nearly half the students $(50.5 \%)$ learn at a fairly regular pace. The fifth-ranked item shows that the way students write papers is also almost evenly divided: just over half (51.85) start to write from the beginning of a paper then progress forward and just under half tend to write sections in random order and then put them together.

\subsection{Factor analysis of a 20-item ILS}

The factor analysis with 20 items from the ILS produced a 4-factor solution with items from only one learning style in each factor prioritised in a decreasing order: Sensing/Intuitive, Visual/Verbal, Active/Reflective and Sequential/Global scales, respectively (Table 4). This method produced a four-factor solution. All the factor loadings were above 0.4 , thus all the items in this analysis of the ILS correlate moderately or highly with the related factor.

Principal component analysis of the 20 items ( 20 statements $\times 2$ sentence endings, $\mathrm{N}=218$ ) showed that eight factors had eigenvalues greater than 1.00 . Kaiser's (1960) study is the most widely used that proposes only retaining factors with eigenvalues greater than 1 . This analysis followed by varimax rotation resulted in four factors with eigenvalues greater than 1 (Table 4). Using factor loadings greater than \pm 0.40 , there were four factors after varimax rotation with Kaiser normalization. Among the 20 items, 12 are considered in the four factors:

Table 4 Factor analysis for 20-item version of ILS

\begin{tabular}{|c|c|c|c|c|}
\hline \multirow[t]{3}{*}{ Item no. } & \multicolumn{2}{|c|}{ Learning style } & \multicolumn{2}{|c|}{ Knowledge building } \\
\hline & Factor 1 & Factor 2 & Factor 3 & Factor 4 \\
\hline & Sensing/Intuitive & Visual/Verbal & Acting/Reflecting & Sequential/Global \\
\hline 18 & 0.757 & & & \\
\hline 6 & 0.754 & & & \\
\hline 38 & 0.635 & & & \\
\hline 31 & & 0.720 & & \\
\hline 27 & & 0.679 & & \\
\hline $7 \mathrm{I}$ & & 0.619 & & \\
\hline 37 & & & 0.665 & \\
\hline 5 & & & 0.620 & \\
\hline 29 & & & 0.429 & \\
\hline 32 & & & & 0.668 \\
\hline 24 & & & & 0.628 \\
\hline 8 & & & & 0.504 \\
\hline
\end{tabular}

Extraction Method: Principal Component Analysis.Rotation Method: Varimax with Kaiser Normalization. ${ }^{\mathrm{a}}$ Rotation converged in 12 iterations. 
Factor 1 (eigenvalue $=1.88,9.39 \%$ of total variance) loaded on three Sensing/Intuitive items (18, 6 and 38);

Factor 2 (eigenvalue $=1.84,9.19 \%$ of total variance) loaded on three Visual/ Verbal items (31, 27 and 7);

Factor 3 (eigenvalue $=1.51,7.57 \%$ of total variance) loaded on three Active/ Reflective items (37, 5 and 29);

Factor 4 (eigenvalue $=1.48,7.41 \%$ of total variance) loaded on three Sequential/Global items (32, 24 and 8).

\subsection{Relationship of interior design studio grades to learning scales}

When the interior design studio grades were the dependent variable and the four learning scales were the independent variables, two-way analysis of variance was conducted. Considering each scale, the Sequential/Global was the only one where the mean score was significantly higher $(\mathrm{p}<0.001)$, with a small effect $\left(\eta^{2}=0.161\right)$. The Active/Reflective, Sensing/Intuitive, Visual/Verbal and Sequential/Global scales were statistically significant at the 0.05 level.

The interactions between the Active/Reflective and Sensing/Intuitive scales $\left(\eta^{2}=0.182\right)$ and between the Active/Reflective and Sequential/Global scales $\left(\eta^{2}=0.105\right)$ were significant at the $p<0.001$ level, with small effects. The interaction between the Active/Reflective and Visual/Verbal scales was statistically significant at the 0.05 level. Furthermore, the interactions among the Active/Reflective, Visual/Verbal and Sequential/Global scales were statistically significant at the 0.05 level, as summarized in Table 5 .

Table 5 Analysis of variance summary table

\begin{tabular}{|c|c|c|c|c|c|}
\hline Source of variation & $\begin{array}{l}\text { Sum of } \\
\text { squares }\end{array}$ & $\begin{array}{l}\text { Degrees of } \\
\text { freedom }\end{array}$ & Mean square & F-ratio & Probability \\
\hline Active/Reflective & 5.08 & 4 & 1.27 & 3.27 & $<0.05$ \\
\hline Sensing/Intuitive & 6.25 & 4 & 1.56 & 4.03 & $<0.05$ \\
\hline Visual/Verbal & 5.79 & 4 & 1.45 & 3.74 & $<0.05$ \\
\hline Sequential/Global & 12.11 & 4 & 3.03 & 7.81 & $<0.001$ \\
\hline Active/Reflective with sensing/Intuitive & 14.09 & 7 & 2.01 & 5.19 & $<0.001$ \\
\hline Active/Reflective with visual/Verbal & 5.43 & 3 & 1.81 & 4.66 & $<0.05$ \\
\hline Active/Reflective with sequential/Global & 7.39 & 3 & 2.47 & 6.36 & $<0.001$ \\
\hline Sensing/Intuitive with visual/Verbal & & & & & Not significant \\
\hline Sensing/Intuitive with sequential/Global & 6.94 & 6 & 1.16 & 2.98 & $<0.05$ \\
\hline Visual/Verbal with sequential/Global & & & & & Not significant \\
\hline $\begin{array}{l}\text { Active/Reflective with sensing/Intuitive with } \\
\text { visual/Verbal }\end{array}$ & & & & & Not significant \\
\hline $\begin{array}{l}\text { Active/Reflective with visual/Verbal with } \\
\text { sequential/Global }\end{array}$ & 2.27 & 1 & 2.27 & 5.86 & $<0.05$ \\
\hline $\begin{array}{l}\text { Sensing/Intuitive with visual/Verbal with } \\
\text { sequential/Global }\end{array}$ & & & & & Not significant \\
\hline $\begin{array}{l}\text { Active/Reflective with sensing/Intuitive with } \\
\text { visual/Verbal with sequential/Global }\end{array}$ & & & & & Not significant \\
\hline
\end{tabular}




\section{Discussion}

\subsection{On the distribution of learning scales}

This study showed that learning style preference did not differ significantly among the Active/Reflective, Sensing/Intuitive, Visual/Verbal and Sequential/Global scales according to student year of study. However, using the ILS, Mostafa and Mostafa (2010) found that second-year architecture students were more active and reflective than first-year architecture students. The authors concluded that there is shift towards a more active-learning mode as students' progress through university. Since both studies used the same ILS instrument, the difference between Mostafa and Mostafa's (2010) study and this study can perhaps be explained by variations in student curriculum, as the former study involved architecture students and the latter involved interior architecture students.

The findings of this study are also different than Tucker's (2007) study, in which he stated that there is a significant relationship between learning styles and year of study. He used Kolb's LSI and compared first- and third-year students' learning styles in architecture, construction management and a combination of these programs. Tucker (2007: 246) concluded that the learning style of design students moves 'towards the abstract conceptualisation mode of the learning process as students near the completion of their studies'. This study did not confirm a shift in the scales towards any pole in the upper years. This difference may be either because of the use of different learning style instruments or because of the difference in program disciplines.

\subsection{On the priority of the learning scales}

The primary factor in this study is composed of three positively loaded Sensing/Intuitive items. The primary finding for the interior architecture students was that they preferred a sensing learning style; that is, learning facts and concrete material. They would also prefer to learn concrete material instead of concepts and theories. While learning new material, the students preferred to talk about it rather than think about it. As Graf, Viola, Leo, and Kinshuk (2007) found in their study of students in information technology programs, sensing learners are more realistic, sensible and practical than intuitive learners. Sensing learners also relate the learned material to the real world. The ILS's Sensing/Intuitive scale is similar to Kolb's (1984) 'perceive' dimension. Although Demirkan and Demirbas (2008) study and this study used different instruments (K-LSI and ILS), the findings that determined that engaging in perceiving activities is the preferred type of learning style for freshman interior architecture students lie parallel to each other.

The secondary factor in this study is composed of three positively loaded Visual/Verbal items. The students of this study preferred a visual information 
input channel. As visual learners, they learn best seeing pictures, diagrams and films. Remembering and recognizing previous information also occurred as visual pictures in their minds. Furthermore, they preferred teaching methods that present visual information rather than text or verbal explanations. As interior architecture education is mostly based on visual material, it is not surprising that visual learners would gravitate to such a profession. In Graf et al. (2007), students preferred written text and spoken words, which is also not surprising given that information technology students were the subjects of that study.

The tertiary factor is composed of three positively loaded Active/Reflective items. In socially oriented behaviour, students considered themselves 'outgoing' rather than 'reserved'. When students learn something new they said they wanted to talk about it, and that they remember things that they have physically done better than they remember things they had not done themselves. As active learners, they tended to understand and learn information best by doing something active such as discussing or applying the material in a course. The findings around the Active/Reflective scale are similar to Kolb's (1984) 'process' dimension. The findings of this study also supports previous work based on Kolb's Experiential Learning Theory (Demirkan \& Demirbas, 2008: 263), which found interior architecture students are 'not reserved ... during the design process'. The authors also stated that interior architecture students are near the active experimentation end of the process axis.

The quaternary factor is composed of three positively loaded Sequential/ Global items and is related to student preferences around the progression of understanding relevant information. The distribution of the interior architecture students was balanced in these items. As sequential learners, nearly half the students learned at a fairly regular pace and began writing from the beginning of a paper and progressed forward. In contrast, global learners use a holistic approach to learning and essay writing and learn broad knowledge better first, breaking it down into parts later. Durling et al. (1996) stated that students studying design (product design, interior design, graphic design, furniture design and design marketing) generally seem to prefer a flexible, global teaching style compared to non-design students (business managers and mechanical engineers), who prefer a more sequential and structured approach. In Graf et al.'s (2007) study of information technology students, students also had less preference for sequential learning.

\subsection{On the relationship of interior design studio grades to learning scales}

The two-way analysis of variance showed that significant effects were obtained in all four scales when interior design studio grades were the dependent variable. The Sequential/Global scale, which shows a student's progression in 
understanding relevant information, was the only scale where the mean score was significantly higher than the other scales. This result may be a reflection of interior architecture education, which teaches building a mental imagery of the final design solution before sketching.

Furthermore, double interactions between Active/Reflective, with Sensing/ Intuitive, scales, Visual/Verbal scales and Sequential/Global scales were significant as were triple interactions among Active/Reflective, Visual/Verbal and Sequential/Global. These findings emphasize that the Active/Reflective scale, which shows students' preferences in information processing, is a dominant scale in interior architecture education. Schon (1984) called this scale a 'reflection-in-action' process in the design studio and Kolb (1984) called it the 'process dimension'.

\section{Implications for interior architecture education}

According to the findings, the interior architecture students were balanced on the Active/Reflective and Sensing/Intuitive scales. A moderate to strong preference on the Visual/Verbal scale and a weak preference on the Sequential/ Global scale were observed. Felder (1996) noted that since instructional approaches present information in ways that appeal to all types of learning methods, it is important to consider all learning styles in teaching. According to Felder (1993: 289), it is important 'not to determine each student's learning style and then teach to it exclusively, but to teach around the learning cycle'.

The role of an instructor is not only to teach new information but also to guide students' education experiences by encouraging them to learn, explore and apply new information in new ways. Characteristically for design education students, their visual scores were high. Designers prefer visual information and they effectively perceive pictures, sketches, film and demonstrations. Therefore, it is advisable to 'use pictures, schematics, graphs and simple sketches liberally before, during and after the presentation of verbal material. Show films. Provide demonstrations, hands-on' activities (Felder \& Silverman, 1988: 680). However, during lectures students should have associated reading materials and discussions about them to improve their verbal skills. Interior architecture is a multidisciplinary profession and requires a variety of skills (Nussbaumer, 2001), such as imaginative abilities and analytical decisionmaking skills. Demonstrating the logical flow of individual course topics, but also pointing out the links between the current material and previously discussed material in the same course is advised by Felder (1993).

The curriculum of an interior architecture program is composed of different courses that can be grouped as technology-based, artistic and the design studio. As Demirbas and Demirkan (2007) pointed out, some learning styles might be more effective than others, depending on the type of course offered 
(e.g. technology-based or artistic). In order to teach around the learning cycle, instructors should select a teaching strategy that meet the needs of all learning styles and prepare sources involving each learning style. To consider both sensing and intuitive learners in perceiving information, the content of the course must be practical (that is, related to real world) as well as innovative, and the methods should allow both for presenting facts and procedures that follow previously used techniques as well as for discussing theory and meanings with abstractions. To accommodate visual and verbal learners alike, the course content should have visual, oral and textual components, and the requested homework/reports should include visualization activities as well as written essays and oral presentations. Information gathering should comprise both visual and textual representations. The instructor could request both diagrams and/or abstracts that summarize the required homework/reports. In considering both active and reflective learners methods of processing information, course content should provide discussion, group presentations and implementation opportunities as well as ways to observe and experience the cases. The requested homework/reports should involve both individual and team work. Considering sequential and global learners equally, some requested homework should consist of small orderly steps that are logically associated with the problem being solved while others should take a holistic approach that allows seeing everything as a whole.

However, in the design studio all learning styles can be effective at different stages of the design process from conceptual to final design. Therefore, instructors should teach via all learning styles to encourage equal development of students' skills. Assigned design projects should require a variety of learning tasks that involve various knowledge sources with various input channels, such as reading texts from books, magazines, digital sources and Internet sources. The sources should provide both verbal and visual information. Also, case studies related to similar projects should be analysed and their advantages and limitations should be discussed. These projects can be stored on a public domain to be accessed by all students.

The collaborative studio process should involve design teams composed of students with different learning styles. Various techniques should be used in developing a design project, such as brainstorming, discussion sessions and role-playing techniques. Several client types can be defined for the same design project, where each group designs to the needs of a different type. In presentation sessions, different approaches to the project should be discussed among students and instructors so each group can acquire knowledge from the others.

It is found that learning styles and gender were independent for interior architecture students regarding the Active/Reflective, Visual/Verbal and Sequential/Global scales. There was a difference between genders only on the Sensing/Intuitive scale, with the males as moderate sensing learners and the 
females having balanced preferences. These findings contrast Demirbas and Demirkan's (2007) study that used the K-LSI; the authors found that learning-style preferences did not significantly differ by gender in all three consecutive first-year design students. Previous studies related to design education using Felder's ILS (Mostafa \& Mostafa, 2010; Tucker, 2007, 2009) did not consider the gender issue.

The current study's contribution lies in determining the priorities of interior architecture students via the four scales of the revised ILS model. Furthermore, the related items within the context of the design process for each scale are specified. Using principal component analysis, this study determined the priorities for interior architecture students regarding Sensing/Intuitive, Visual/Verbal, Active/Reflective and Sequential/Global scales (in that decreasing order). Each scale was identified by three positively loaded related items on that scale. This priority list should guide design instructors in providing a better learning experience for their students.

Finally, providing a balance of support and challenge for the interior design student can promote a technology-enhanced active design studio, where instructors are knowledge facilitators who positively affect students' learning experiences by encouraging them to acquire, explore and apply new information in new ways to their design projects. This structure appears to provide effective student engagement through discussion and collaboration, resulting in significant benefit for the students.

Further studies could examine the importance of these items in technology enhanced learning environments to help teachers shift from an instructorcentric to a student-centric approach. Differences across design disciplines, such as industrial design and architecture programs, or across institutions, such as public and private or small and large, could also be analysed. Further, common dimensions with other learning style analyses, such as Kolb's or the MBTI, could be explored in the context of design education.

\section{Acknowledgment}

The author would like to thank to the anonymous reviewers for their constructive feedback and valuable insights in improving the paper.

\section{References}

Barsalau, L. W., Simmons, W. K., Barbey, A. K., \& Wilson, C. D. (2003). Grounding conceptual knowledge in modality-specific systems. Trends in Cognitive Sciences, 7(2), 84-91.

Carmel-Gilfilen, C. (2012). Uncovering pathways of design thinking and learning: inquiry on intellectual development and learning style preferences. Journal of Interior Design, 37(3), 47-66.

Cho, J. Y., Cho, M. H., \& Kozinets, N. (2015). Does the medium matter in collaboration? Using visually supported collaboration technology in an interior 
design studio. International Journal of Technology and Design Education1-20, (in press).

Demirbas, O. O., \& Demirkan, H. (2003). Focus on architectural design process through learning styles. Design Studies, 24(5), 437-456.

Demirbas, O. O., \& Demirkan, H. (2007). Learning styles of design students and the relationship of academic performance and gender in design education. Learning and Instruction, 17(3), 345-359.

Demirkan, H. (1998). Integration of reasoning systems in architectural modelling activities. Automation in Construction, 7(2-3), 229-236.

Demirkan, H. (2015). Frameworks for decision-making in design for the aging. In J. A. A. Thompson, \& N. H. Blossom (Eds.), The Handbook of Interior Design (pp. 212-225). UK: Wiley-Blackwell.

Demirkan, H., \& Demirbas, O. O. (2008). Focus on the learning styles of freshman design students. Design Studies, 29(3), 254-266.

Demirkan, H., \& Demirbas, O. O. (2010). The effects of learning styles and gender on the academic performance of interior architecture students. Procedia-Social and Behavioral Sciences, 2(2), 1390-1394.

Durling, D., Cross, N., \& Johnson, J. (1996). Personality and learning preferences of students in design and design-related disciplines. In Proceedings of the International Design and Technology Educational Research and Curriculum Development Conference, IDATER 96. Loughborough: Loughborough University. Available online. http://www.lboro.ac.uk/idater/downloads96/durling96.pdf.

Felder, R. M. (1993). Reaching the second tier: learning and teaching styles in college science education. Journal of College Science Teaching, 23(5), 286-290.

Felder, R. M. (1996). Matters of style. ASEE Prism, 6(4), 18-23.

Felder, R. M., \& Brent, R. (2005). Understanding student differences. Journal of Engineering Education, 94(1), 57-72.

Felder, R. M., \& Silverman, L. K. (1988). Learning and teaching styles in engineering education. Engineering Education, 78(7), 674-681.

Felder, R. M., \& Soloman, B. A. (2004). Index of Learning Styles. www.ncsu.edu/ felder public/ILSpage.html. Accessed 12.06.09.

Felder, R. M., \& Spurlin, J. (2005). Reliability and validity for the index of learning styles: a meta-analysis. International Journal of Engineering Education, 21(1), 103-112.

Graf, S., Viola, S. R., Leo, T., \& Kinshuk. (2007). In depth analysis of the Felder Silverman learning style dimensions. Journal of Research on Technology and Education, 40(1), 1-15.

Hsu, C. H. C. (1999). Learning styles of hospitality students: nature or nurture? Hospitality Management, 18(1), 17-30.

Kaiser, H. F. (1960). The application of electronic computers to factor analysis. Educational and Psychological Measurement, 20(1), 141-151.

Karakaya, A. F., \& Demirkan, H. (2015). Collaborative digital environments to enhance the creativity of designers. Computers in Human Behavior, 42, 176-186.

Kolb, D. A. (1984). Experiential Learning: Experience as the Source of Learning and Development. Englewood Cliffs, NJ: Prentice Hall.

Kvan, T., \& Yunyan, J. (2005). Students' learning styles and their correlation with performance in architectural design studio. Design Studies, 26(1), 19-34.

Lawson, B. (1993). Parallel lines of thought. Languages of Design, 1(4), 357-366.

Litzinger, T. A., Lee, S. H., Wise, J. C., \& Felder, R. M. (2007). A psychometric study of the index of leaning styles. Journal of Engineering Education, 96(4), 309-319. 
Mor, Y., \& Mogilevsky, O. (2013). The learning design studio: collaborative design inquiry as teachers' professional development. Research in Learning Technology, 21.

Mostafa, M., \& Mostafa, H. (2010). How do architects think? Learning styles and architectural education. International Journal of Architectural Research, $4(2-3), 310-317$.

Newland, P., Powell, J., \& Creed, C. (1987). Understanding architectural designers' selective information handling. Design Studies, 8(1), 1-17.

Nussbaumer, L. L. (2001). Theoretical framework for instruction that accommodates all learning styles. Journal of Interior Design, 27(2), 3-15.

Russ, R., \& Weber, M. (1995). Personality types of interior design students: Implications for education. Journal of Interior Design, 21(1), 30-38.

Schmitt, N. (1996). Uses and abuses of coefficient alpha. Psychological Assessment, 8(4), 350-353.

Schon, D. A. (1983). The Reflective Practitioner How Professionals Think in Action. USA: Basic Books/Harper Collins.

Schon, D. A. (1984). The architectural studio as an exemplar of education for reflection-in action. Journal of Architectural Education, 38(1), 2-9.

Smith, D. M., \& Kolb, D. A. (1996). User's Guide for the Learning-style. Boston: McBer and Company.

Tabachnick, B. G., \& Fidell, L. S. (1996). Using Multivariate Statistics (3rd ed.). New York: HarperCollins.

Tucker, R. (2007). Southern drift: the learning styles of first-and third-year students of the built environment. Architectural Science Review, 50(3), 246-255.

Tucker, R. (2009). Getting old and heading south: the academic success of Southerner learners in design cohorts. Higher Education Research \& Development, 28(2), 195-207.

Tuckman, B. W. (1999). Conducting Educational Research (5th ed.). Fort Worth: Harcourt Brace College Publishers. 